\title{
THE SMARTPHONERS: CONSUMER SEGMENTATION BY SMARTPHONE USAGE ${ }^{\circ}$
}

\author{
Francesca De Canio*, Davide Pellegrini* *, \\ Maria Elena Aramendia-Muneta*
}

\begin{abstract}
Smartphone usage is becoming an integral part of consumers' lifestyle. Over 50\% of the worldwide population own at least one smartphone and the adoption of mobile technologies have reshaped the boundaries between online and offline.

This study aims to segment consumers by means of activities they perform on personal mobile phones. By analysing 264 online questionnaires and using ten smartphones' functionalities, we identify five main Smartphoners' profiles: Utility Users, Gamers, Unfriendly Users, Moderator Users and Supersmartphoners. Differences between smartphone users in terms of age, gender and area of residence, as well as brand of the smartphone owned, hours of usage and reasons to use have been investigated. Managerial and academic implications have been discussed.
\end{abstract}

Keywords: Smartphone, Consumer Segmentation, Functionalities, Device Usage, Lifestyle, Cluster Analysis.

\section{Introduction}

The technology scenario is turned over in less than 5 years by the introduction to the market of a new product: The Smartphone. "A smart

- L'articolo nasce dall'idea e dal contributo congiunto di tutti gli autori. Nella elaborazione finale del manoscritto Francesca De Canio ha curato i paragrafi: Introduction, 1, 2, 3, 4, 6, Conclusions; Davide Pellegrini ha curato il paragrafo 5; Maria-Elena Aramendia-Muneta ha curato il paragrafo 3. The authors thank Tommaso Monardi for his support in the earlier stages of this study.

* Corresponding author. Ph.D. Student, Agreement between University of Ferrara and University of Parma, Department of Economics, Via J.F. Kennedy, 6 - 43125 Parma (PR), Italy; e-mail: francesca.decanio@unife.it.

** Associate Professor, University of Parma, Department of Economics, Via J.F. Kennedy, 6 - 43125 Parma (PR), Italy; e-mail: davide.pellegrini@unipr.it.

*** Lecturer, Universidad Pública de Navarra, Department of Business Administration, Edificio Madroños, Campus Arrosadia s/n, 31004 Pamplona, Spain; email: elena.aramendia@unavarra.es.

Mercati e Competitività n. 1, 2016 
phone is a next-generation, multifunctional cell phone that provides voice communication and text-messaging capabilities and facilitates data processing as well as enhanced wireless connectivity" (Zheng and $\mathrm{Ni}$, 2006). By the early 90s, it started the development of a phone in which the normal phone's functions were integrated with general computers and PDAs' functions. At the end of the year 2006, Apple announced the launch of a new product called iPhone and on $9^{\text {th }}$ January 2007 the first iPhone was launched. Although the spread of smartphone started in the first years slowly, only $6 \%$ of mobile phones were smartphones (De Gusta, 2012), thanks to the recent spread of internet, the value of this product grew considerably reshaping the telecommunication market.

In fact, at the early stage of its launch in the market, the smartphone was considered as an experience good (Yoo et al., 2010). Today we can consider this product as a commodity, due to the increase popularity during the last five years (Park and Chen, 2007), reaching the majority of consumers. Nowadays at least, half of world population owns a smartphone (GSMA, 2015) and it is expected to reach $80 \%$ by 2020 (The Economist, 2015). In line with Rogers's innovation adoption theory (1995) in its early stage, most consumers hesitate to purchase smartphones, but thanks to the spread of technology, any more users adopt it. Thus, smartphone is becoming an essential innovative technology gadget for working executives, providing flexibility to consumers at anytime, anywhere they are (Bojei and Hoo, 2012).

Smartphone has a profound effect on people lifestyles because it changes the way people live, work and learn (Hamka et al., 2014). The new functionalities manufacturers launch every year, allow consumers to interact through voice call, text messages, social networks and games, and enable them to surf online, listen music and take pictures, among others.

Moreover, the growing importance of smartphone, not only as a product but also as a mobile device, constantly in touch with consumers, is arousing the interest of scholars and of actors of the mobile ecosystem (e.g. handset manufacturers, mobile application providers and telecommunication operators). In fact, the adoption of mobile technologies is reshaping the boundaries between online and offline. Consumers are much more connected through their mobile devices and the spread of internet, social media and the ubiquitous device are generating new opportunities for marketers, which stay in touch with their consumers every time and everywhere.

In marketing and retailing practices, the spread of new devices and above all the smartphone is transforming the economic scenario (Verhoef et al., 2015; Zhang et al., 2010). The smartphone is recognized as a great in-store support during the consumer shopping experience (Karaatli and Veryzer, 2012) and recently it is evolving its role in the shopping process 
The Smartphoners: consumer segmentation by smartphone usage

(Google, 2012). Indeed, the growing importance that the mobile-retailing is gaining in the online shopping, makes the m-commerce an emerging retailing format (Hung et al., 2012; Zhang et al., 2010; Lu and Su, 2009). On the one hand, consumers use multiple devices to shopping online, on the other hand, smartphone users are recognized as more valuable in a long-time relation between providers/retailers and consumers (De Canio et al., 2015). Consequently, today smartphone represents the leading mobile device for communication, information and entertainment (Choi and Lee, 2012) as well as shopping (Zhang et al., 2010). Particularly in Italy, where the spread of smartphones reaches $64.1 \%$ of Italian population (ComScore, 2014), making the smartphone owners and users (hereinafter "Smartphoners") an interesting segment.

Therefore, the growing importance of smartphone in consumers' lifestyles as well as in business is leading the development of researches focused on this product. Joining in this research area, this paper aims to develop consumer market segments based on smartphone usage. By the use of ten of the major smartphone's functionalities, we will identify the main segments of smartphoners. We finally analyse smartphoners' profiles in terms of demographic (age, gender) geographic (living area) and behavioural (hours of smartphone usage per day, reasons to use and the brand of the smartphone owned) differences.

\section{Theoretical Background}

Nowadays, the market of technological tools is seeing a surge in sales of mobile devices (e.g. smartphones, tablets, etc.) at the expense of computers. This is favouring the convergence of online shopping to a mobile system, indeed as available hic et nunc, rather than tied to a default place and context. Thus, the growth in wireless technologies is pushing companies to concentrate their investments in the development of systems capable to support the use of mobile in different context as communication (Venkatesh, 2015; Shankar and Balasubramanian, 2009) and commerce (Ström et al., 2014; Chong, 2013; Hung et al., 2012; Shankar et al., 2010, Zhang et al., 2010; Lu and Su, 2009).

To date, the two key variables of mobile usage are its accessibility regardless of time and place (Hill and Roldan, 2005; Chen and Nath, 2004; Balasubramanian et al., 2002). Likewise, mobiles' technologies enable customer interactions (Kumar and Zahn, 2003) and playfulness (Chong, 2013) and allow discussion groups and access to informational content and knowledge at anytime and anywhere (Groß, 2015; Chang et al., 2003; Roschelle, 2003) in a new augmented social context via social networks and mobile apps. Thus, the opportunity the mobile technology develops is 


\section{F. De Canio, D. Pellegrini, M.E. Aramendia-Muneta}

to create a new augmented social reality in which boundaries between online and offline lifestyle are blurring.

According to Persaud and Azhar (2012, p. 419) "while consumers adopt mobile phones to enhance their private and social lives, marketers see mobile phones as a marketing channel". In fact, similarly to consumers, the new mobile devices are creating opportunities and advantages also for companies. Indeed, the additional value created by mobile services for companies is that they can customize the offer in terms of time, location and personal profile (Figge, 2004), improves communication and sales (Ström et al., 2014; Shankar and Balasubramanian, 2009; Mamaar, 2003) and potentially increases retailer effectiveness and efficiency. Most of the studies on smartphones are related to the adoption and use of smartphone technology such as adoption and acceptance, functionality and performance, software and security, networking and connectivity (Aldhaban, 2012). The holistic approach to the adoption of smartphone as whole product has not been explored enough (Aldhaban, 2012; Kang et al., 2011).

\subsection{The market segmentation}

The concept of market segmentation was firstly introduced by Smith (1956) as a method to focus on different preference and desire of consumers in creating a more satisfying offer. Indeed, "goods can no longer be produced and sold without considering customer needs and recognizing the heterogeneity of those needs" (Wedel and Kamakura, 2000, p. 3). Indeed, the ability to propose a diversified offer according to specific need of groups of customers or sub-markets gets companies a competitive advantage. The consumers' profiles are identified via cluster analysis, which is a multivariate technique used to split respondents into homogeneous groups (Scott and Knott, 1974). It is becoming a common tool in marketing research to identify consumers' segments, because they provide information about habits and relevant characteristics of their daily life.

In literature, four main segmentation techniques commonly used in consumer profile definition are: demographic, geographic, psychographic and behavioural (Kotler, 2003). The two main criteria that have been accomplished in a segmentation are: homogeneity within groups and uniqueness between groups through the study of the variance of each respondents respect to the overall mean.

Despite the initial stage of literature in the field of smartphone segmentation, the growing attention of scholars and marketers is strongly 
The Smartphoners: consumer segmentation by smartphone usage

pushing the development of this research topic. In agreement with Groß (2015), this topic will explode over the coming 24 months.

It is becoming paramount both for researcher and actors of the mobile ecosystem understanding how consumers interact with their mobile devices and what the main factors influencing the shopping of smartphone are. The main studies segmenting the smartphoners have focused on: services consumers preference (Aarnio et al., 2002; Sell et al., 2010), intention to use or perceived benefits (Sell et al., 2014), usage of voice call and SMS (Lin, 2007), perceived acceptance and usage of smartphone (Groß, 2015) and cultural influences on smartphone adoption (De Marez et al., 2007; Muk, 2007), and countries' development differences in mobile telecommunication (Banerjee and Ros, 2004). Along with this, we have some studies on consumers' segmentation based on smartphone functionalities. For example, Vanden Abeele et al., (2014) disclose among the youth users three different segments: the trendy users, strongly embedded in social and fashionable characteristics of their smartphones, the engaged users, characterized by an instrumental and social use of mobile phone and the thrifty users, with a basic and disinterested use of mobile phone. Goneos-Malka et al., (2014) identify four different segments: the Conventionalists, inclined to limit their smartphone usage, the Connectors who basically use communication functions, the Technoisseurs, who have a whole use of mobile phone facilities, and the expert users, the Mobilarti.

\section{Methodology}

Data was gathered via an online survey website and launched through Facebook. The post was shared on Facebook during two weeks, in the first fortnight of May 2015.

\subsection{Measures}

The questionnaire consists of three parts. In the first part, respondents provide several demographic information. The second part contains questions about smartphone usage, such as, the time spent using the mobile device in terms of hours of usage, the brand of the smartphone owned (Apple, Samsung, Others) and the main reason to smartphone use (fun, job, both). In the third part, ten smartphone functions were inquired. We asked respondents to evaluate their usage of each function independently of one another. Respondents have to evaluate their usage of each function from absolutely not use $(0 \%)$ to fully use $(100 \%)$. 


\subsubsection{Smartphone Functions}

"A product consists of functional attributes [...] and each consumer accepts different functional attributes. If a consumer does not receive satisfaction from the influential functional attributes, he or she will not use the product" (Kang et al., 2011, p. 920). Understand which functionalities satisfy consumers' needs is one of the most important goal of marketers as well as scholars. Starting from nineteen recommended features that a smartphone must-have or is desirable-to-have (Chang et al., 2009) we focused on ten main features we consider the most relevant in smartphoners segmentation.

"The smartphone offers flexibility to the executive to be mobile and ability of wireless data and voice communication anytime, anywhere they are" (Bojei and Hoo, 2012, p. 39). Indeed, the voice communication (CALL) is one of the three basic functions of a phone (Goneos-Malka et al., 2014; Chang et al., 2009). The voice call function comes from phones, it was developed in mobile phones and it is solidified in smartphones. Other basic function of a smartphone is the instant message or text message (TXT) that comes from mobile phones functions (Goneos-Malka et al., 2014; Chang et al., 2009). Finally, the most distinctive feature of smartphone is its ability to access internet (Goneos-Malka et al., 2014; Chang et al., 2009). We propose a double description of internet access: a more functional perspective of seeking information on internet (INT) and another more ludic perspective of surfing online (ONL) with the aim of verifying difference in perceived behaviour.

As shown by Kang et al., multimedia function "has become a core [mobile] function that diminishes time or spatial constraints" (2011, p.3). Among the multimedia functions Chang et al., (2009) identify the smartphone capability of taking pictures (PHT), stream video (VID) and play music (MUS). Furthermore, due to the "meteoric rise" of cell phone gaming, game (GAM) is considered another multimedia function (Chang et al., 2009) and more hedonic (Verkasalo et al., 2010).

Mobile consumers have the social need to be connected with others (Kim et al., 2013). To satisfy the hedonic and social need of smartphone users, manufacturers and apps provider integrate the social networks access (SN) in the smartphone function (Goneos-Malka et al., 2014).

Every day mobile application providers develop a large number of augmented functionalities by means of mobile applications. Just in Apple Store, they offered more than 760,000 apps (Monti, 2013). Our last function called mobile applications (APP) would partially include those functionalities. 
The Smartphoners: consumer segmentation by smartphone usage

\subsection{The Sample}

A total of 277 successful questionnaires were collected. As the research design was calibrated on the local market, 9 answers were excluded because they were completed by non-Italian consumers. 4 answers were excluded because they were completed by non-owners of smartphones. Finally, a total of 264 answers were used for the analysis. The final sample of this study includes exclusively real smartphone owners and users in Italy.

The profile of the sample is summarized as follows: male are $75.8 \%$, and female are $24.2 \%$. The average age of the interviewees is 33 year old, from a minimum of 15 years old to a maximum of 71 years old, with the $62 \%$ of the sample younger than 35 years. Almost $55 \%$ of the respondents has a secondary level of education and $15.2 \%$ possesses a bachelor degree. Graduates accounted for $17 \%$ of the respondents, while only $2.3 \%$ have a post-graduate degree. Other categories are residual. $50.4 \%$ possess an iPhone, $34.8 \%$ own a smartphone branded Samsung and $14.8 \%$ have a smartphone of other brands (e.g. Sony, LG, Nokia, Huawei). The sample is heterogeneous in terms of hours of usage of their smartphones: $9.8 \%$ of respondents use the smartphone less than $1 \mathrm{~h} / \mathrm{day}, 43.9 \%$ of the sample use the smartphone 1-3 hours per day, 19.7\% use smartphones 3-5 hours per day and $26.5 \%$ use smartphone more than 5 hours per day. Just a $9.8 \%$ of respondents claim to use smartphone for work, while $27.3 \%$ of them use the smartphone for fun, but the majority of the sample (62.9\%) use the smartphone both for work and for fun.

\subsection{Descriptive Analytics of Smartphone Functionalities}

We asked respondents to indicate how they use the individualized functionalities in their general usage of smartphone. To carry out the analysis, the variables have been transformed from base $100(0 \%-100 \%)$ to base $10(0-10)$. In table 1 , we present the descriptive statistics of the investigated smartphones' functionalities.

The main item they declare to use is the browser internet in seeking information (INT $=6.76$ ), while the less used function seems to be games $(\mathrm{GAM}=2.36)$. The voice call, that were the main function of the traditional phones, turn out to be only the third function $(\mathrm{CALL}=5.65)$ after the use of social networks ( $\mathrm{SN}=5.87$ ).

Particularly evaluable is the marked difference observed between the "Seek information in the Internet" (rank 1) and the "Surf Online" (rank 8). In fact, respondents perceive strongly different to the two variables that we expected would get similar scores. 
F. De Canio, D. Pellegrini, M.E. Aramendia-Muneta

Tab. 1 - Descriptive statistics of the items

\begin{tabular}{llllr}
\hline & \multicolumn{1}{c}{ Item } & Mean & St. Dev & Rank \\
\hline CALL & Voice Call & 5.652 & 3.2242 & 3 \\
TXT & Text Messages & 5.617 & 3.2268 & 4 \\
INT & Seeking Information & 6.765 & 3.1317 & 1 \\
& in the Internet & & & \\
SN & Social Networks & 5.871 & 2.9415 & 2 \\
APP & Mobile Applications & 4.913 & 2.9502 & 5 \\
ONL & Surfing Online & 3.303 & 2.6763 & 8 \\
GAM & Games & 2.364 & 2.6067 & 10 \\
MUS & Music & 3.530 & 3.0965 & 7 \\
PHT & Photos & 4.913 & 3.0615 & 5 \\
VID & Video & 3.068 & 2.5280 & 9 \\
\hline
\end{tabular}

\section{Empirical Analysis}

Data were performed using SPAD statistical software version 5.6 developed by CISIA-CERESTA (Nakache and Confais, 2000; Lebart et al., 2001).

The quantitative research processing was carried out through the following steps: 1) we compute the principal component analysis (PCA), to detect the latent structure of the variables considered, highlighting the use of consumers gives to their smartphones; 2) once the factorial coordinates were obtained with PCA, a factor-based cluster analysis is applied in order to obtain groups. Customers were grouped to describe the relation both to the original variables and to the factors (Abascal et al., 2006).

The Bartlett test of Sphericity $\left(\chi_{(45)}^{2}=1086,464, p\right.$-value $\left.=0.000\right)$ and the $\mathrm{KMO}=0.892$ show the adequacy of the sample. Furthermore, all the variables show communalities equal or greater than 0.50 , showing a good significance of the PCA.

Tab. 2 - Control panel of Eigenvalues (Trace of matrix: 10.00000)

\begin{tabular}{lccc}
\hline Number & Eigenvalue & Percentage & $\begin{array}{r}\text { Cumulated } \\
\text { Percentage }\end{array}$ \\
\hline 1 & 4,5466 & 45,47 & 45,47 \\
2 & 1,1170 & 11,17 & 56,64 \\
3 & 0,8402 & 8,40 & 65,04 \\
4 & 0,7343 & 7,34 & 72,38 \\
5 & 0,6861 & 6,86 & 79,24 \\
6 & 0,5357 & 5,36 & 84,60 \\
7 & 0,4979 & 4,98 & 89,58 \\
8 & 0,4032 & 4,03 & 93,61 \\
9 & 0,3463 & 3,46 & 97,07 \\
10 & 0,2926 & 2,93 & 100,00 \\
\hline
\end{tabular}


The Smartphoners: consumer segmentation by smartphone usage

As can be seen, the first two components explain near $57 \%$ of the variability of the phenomenon (Tab. 2). Only the first and second values are high enough to draw relevant conclusions, because their magnitudes are over one. Both axes explain roughly $57 \%$ of the information provided by the sample.

Tab. 3 - Active variables-factors correlations

\begin{tabular}{lrrrrr}
\hline Label variable & Axis 1 & Axis 2 & Axis 3 & Axis 4 & Axis 5 \\
\hline Call & 0,72 & $-0,22$ & $-0,03$ & 0,34 & $-0,35$ \\
Text & 0,67 & 0,00 & $-0,27$ & 0,51 & 0,10 \\
Internet & 0,80 & $-0,12$ & $-0,34$ & $-0,11$ & 0,05 \\
SN & 0,68 & $-0,07$ & $-0,41$ & $-0,35$ & 0,22 \\
Apps & 0,70 & 0,12 & $-0,02$ & $-0,40$ & $-0,15$ \\
Online & 0,68 & $-0,23$ & 0,37 & $-0,10$ & $-0,40$ \\
Games & 0,33 & 0,82 & $-0,11$ & $-0,03$ & $-0,33$ \\
Music & 0,59 & 0,49 & 0,22 & 0,20 & 0,34 \\
Fotos & 0,79 & $-0,25$ & 0,06 & 0,05 & 0,12 \\
Video & 0,68 & 0,02 & 0,53 & $-0,10$ & 0,29 \\
\hline
\end{tabular}

The first axis weighs nine out ten uses of the smartphone and the second only the game as a use (Table 3). The second axis reflects the use of games in smartphones, which proved to be is remarkably informative because correlations are relevant and all of them have the same signs, positive, so all the variables are located and projected on the right side of the first axis.

The results of the reliability of data using Cronbach's alpha is 0.876 . Hair et al., (1998) recommended that a value higher than 0.7 as acceptable. According to our results, values are reliable and suitable for further analysis.

Cluster analysis (Table 4) identifies homogeneous groups of consumers based on 10 mobile devices' functionalities. Socio-demographic indicators (gender and age), and behavioural variables (hours of use, brand of the smartphone owned, reason of the use of smartphone) have been analysed.

Tab. 4 - Cluster Analysis

\begin{tabular}{lcc}
\hline N. cluster & N. cases & $\%$ \\
\hline 1 & 66 & $25.5 \%$ \\
2 & 33 & $12.5 \%$ \\
3 & 79 & $29.9 \%$ \\
4 & 53 & $20.1 \%$ \\
5 & 33 & $12.5 \%$ \\
\hline
\end{tabular}




\section{Results and Discussion}

\subsection{Smartphoners Profiles}

The five targets of the identified smartphoners through the main functions used are presented in figure 1. Demographic and behavioural differences have been statistically tested between clusters.

Fig. 1 - Cluster Distribution

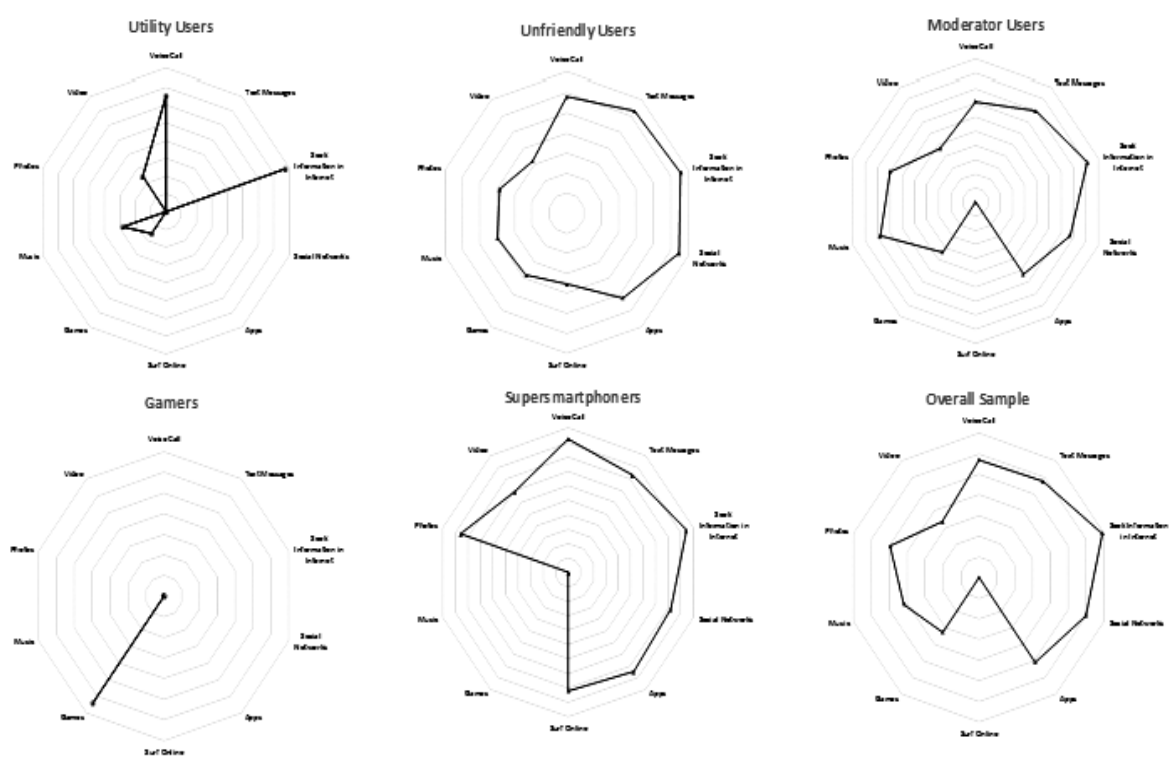

\subsubsection{Utility Users}

Interviewers that use mobile phone devices as a utilitarian phone device compose the first cluster. In fact, those consumers use basically voice call and internet to seek information (Table 5). They do not like using smartphone to play games, listen to music and make videos. For those consumers the proposed digital functionalities for a more valuable product seem to have no success. No significant differences have been found between this cluster and the overall mean of the sample in terms of demographic and behavioural variables. 
The Smartphoners: consumer segmentation by smartphone usage

Tab. 5 - Utility Users

\begin{tabular}{lcccccc}
\hline Variables & $\begin{array}{c}\text { Cluster } \\
\text { mean }\end{array}$ & $\begin{array}{c}\text { Overall } \\
\text { mean }\end{array}$ & $\begin{array}{c}\text { Cluster Std. } \\
\text { deviation }\end{array}$ & $\begin{array}{c}\text { Overall Std. } \\
\text { deviation }\end{array}$ & $\begin{array}{c}\text { Test- } \\
\text { value }\end{array}$ & p-value \\
\hline INT & 7.75 & 6.90 & 2.11 & 3.01 & 2.65 & 0.004 \\
CALL & 6.54 & 5.69 & 2.67 & 3.19 & 2.45 & 0.007 \\
VID & 2.45 & 3.32 & 1.42 & 2.46 & -3.27 & 0.001 \\
MUS & 2.81 & 4.20 & 1.56 & 2.92 & -4.16 & 0.000 \\
GAM & 1.50 & 3.27 & 0.81 & 2.53 & -5.73 & 0.000 \\
\hline
\end{tabular}

\subsubsection{Gamers}

We call the second target of consumers Gamers. The main feature of this cluster is that they use smartphone mainly for play (Table 6). This trend is in line with the main aims of handset manufacturers, mobile application developers and phone operators that are trying to engage smartphone users by the use of hedonic features. In fact, they are increasingly develop mobile interfaces that capture the ludic attitude of users. Even in literature, enjoyment and playfulness are commonly studied to explain the attitude towards the use of smartphone. T-test on the demographic and behavioural variables do not show statistical differences between the Gamers and the overall mean of the total sample.

Tab. 6 - Gamers

\begin{tabular}{lcccccc}
\hline Variables & $\begin{array}{c}\text { Cluster } \\
\text { mean }\end{array}$ & $\begin{array}{c}\text { Overall } \\
\text { mean }\end{array}$ & $\begin{array}{c}\text { Cluster Std. } \\
\text { deviation }\end{array}$ & $\begin{array}{c}\text { Overall Std. } \\
\text { deviation }\end{array}$ & $\begin{array}{c}\text { Test- } \\
\text { value }\end{array}$ & p-value \\
\hline GAM & 6.419 & 3.267 & 1.519 & 2.531 & 7.56 & 0.000 \\
\hline
\end{tabular}

\subsubsection{Unfriendly Users}

The Unfriendly Users is a target of consumers that absolutely do not like the use of any function available in mobile phone devices (Table 7). It seems that these users, although they possess a smartphone, are being compelled to follow technological trends and have to adapt to those. They evaluate negatively all the functionalities of the owned smartphone with particular relevance for the use of internet, photos and social networks. 
F. De Canio, D. Pellegrini, M.E. Aramendia-Muneta

Tab. 7 - Unfriendly Users

\begin{tabular}{lcccccc}
\hline Variables & $\begin{array}{c}\text { Cluster } \\
\text { mean }\end{array}$ & $\begin{array}{c}\text { Overall } \\
\text { mean }\end{array}$ & $\begin{array}{c}\text { Cluster Std. } \\
\text { deviation }\end{array}$ & $\begin{array}{c}\text { Overall Std. } \\
\text { deviation }\end{array}$ & $\begin{array}{c}\text { Test- } \\
\text { value }\end{array}$ & p-value \\
\hline GAM & 1.913 & 3.267 & 1.231 & 2.531 & -4.15 & 0.000 \\
VID & 1.603 & 3.320 & 0.968 & 2.460 & -6.42 & 0.000 \\
MUS & 2.000 & 4.198 & 1.257 & 2.925 & -6.57 & 0.000 \\
ONL & 1.773 & 3.664 & 1.152 & 2.568 & -7.02 & 0.000 \\
TXT & 3.160 & 5.770 & 2.129 & 3.126 & -8.58 & 0.000 \\
APP & 2.616 & 5.086 & 1.818 & 2.845 & -8.76 & 0.000 \\
CALL & 2.910 & 5.695 & 2.107 & 3.192 & -9.18 & 0.000 \\
SN & 3.240 & 5.985 & 1.780 & 2.847 & -9.88 & 0.000 \\
PHT & 1.935 & 4.969 & 1.073 & 3.027 & -10.46 & 0.000 \\
INT & 3.289 & 6.896 & 1.904 & 3.010 & -12.40 & 0.000 \\
\hline
\end{tabular}

A majority of men over 35 years joins this group and they spend less than 1 hour per day using their smartphone (Table 8).

Tab. 8 - Characterisation by categories of groups

\begin{tabular}{lccccccc}
\hline Variab. & Categ. & $\begin{array}{c}\text { \% of } \\
\text { Categ. } \\
\text { in group }\end{array}$ & $\begin{array}{c}\text { \% of } \\
\text { Categ. } \\
\text { in set }\end{array}$ & $\begin{array}{c}\text { \% of } \\
\text { group in } \\
\text { Categ. }\end{array}$ & $\begin{array}{c}\text { Test- } \\
\text { value }\end{array}$ & p-value & Weight \\
\hline Use & -1 hour & 17.72 & 9.85 & 53.85 & 2.49 & 0.006 & 26 \\
$\begin{array}{l}\text { Age- } \\
\text { Gender }\end{array}$ & Man +35 & 39.24 & 28.03 & 41.89 & 2.47 & 0.007 & 74 \\
\hline
\end{tabular}

\subsubsection{Moderated Users}

The Moderator Users are those who use all the functions available on their mobile phone device. This target of consumers basically appreciate all the functionalities provide by manufacturers and use them more than the average of the other users (Table 9). The main activity they perform on their smartphone is seeking information on the internet, while no particular differences have been found on respect of the surfing online. They have a utilitarian approach to the device, and use it as a tool that englobes different functionalities, all of them useful in different context. No particular demographic and behavioural characteristics have been found in this group of consumers. 
The Smartphoners: consumer segmentation by smartphone usage

Tab. 9 - Moderated Users

\begin{tabular}{lcccccc}
\hline Variables & $\begin{array}{c}\text { Cluster } \\
\text { mean }\end{array}$ & $\begin{array}{c}\text { Overall } \\
\text { mean }\end{array}$ & $\begin{array}{c}\text { Cluster Std. } \\
\text { deviation }\end{array}$ & $\begin{array}{c}\text { Overall Std. } \\
\text { deviation }\end{array}$ & $\begin{array}{c}\text { Test- } \\
\text { value }\end{array}$ & p-value \\
\hline MUS & 7.784 & 4.198 & 1.661 & 2.925 & 9.95 & 0.000 \\
INT & 9.151 & 6.896 & 1.337 & 3.010 & 6.10 & 0.000 \\
TXT & 7.962 & 5.770 & 2.434 & 3.126 & 5.72 & 0.000 \\
PHT & 6.981 & 4.969 & 2.269 & 3.027 & 5.41 & 0.000 \\
SN & 7.717 & 5.985 & 2.175 & 2.847 & 4.96 & 0.000 \\
VID & 4.679 & 3.320 & 2.417 & 2.460 & 4.54 & 0.000 \\
CALL & 7.113 & 5.695 & 2.560 & 3.192 & 3.62 & 0.000 \\
APP & 6.340 & 5.086 & 2.532 & 2.845 & 3.60 & 0.000 \\
GAM & 4.372 & 3.267 & 2.702 & 2.531 & 3.24 & 0.001 \\
\hline
\end{tabular}

\subsubsection{Supersmartphoners}

Supersmartphoners are smartphone users that have made the smartphone as the main tool they use to make pictures and videos and to share those on social networks (Table 10). The smartphone is also a socialized tool that they use to stay in contact with others. In fact, they have a wider use of the smartphone, especially, voice call. Voice call and seek information are much more performed by those customers than the other users. No statistical demographic and behavioural differences have been found between the Supersmartphoners and the overall mean of respondents.

Tab. 10 - Supersmartphoners

\begin{tabular}{lcccccc}
\hline Variables & $\begin{array}{c}\text { Cluster } \\
\text { mean }\end{array}$ & $\begin{array}{c}\text { Overall } \\
\text { mean }\end{array}$ & $\begin{array}{c}\text { Cluster Std. } \\
\text { deviation }\end{array}$ & $\begin{array}{c}\text { Overall Std. } \\
\text { deviation }\end{array}$ & $\begin{array}{c}\text { Test- } \\
\text { value }\end{array}$ & p-value \\
\hline ONL & 8.212 & 3.664 & 1.513 & 2.568 & 10.94 & 0.000 \\
VID & 6.906 & 3.320 & 2.141 & 2.460 & 8.83 & 0.000 \\
APP & 8.485 & 5.086 & 1.777 & 2.845 & 7.34 & 0.000 \\
PHT & 8.576 & 4.969 & 1.670 & 3.027 & 7.31 & 0.000 \\
CALL & 9.242 & 5.695 & 1.577 & 3.192 & 6.82 & 0.000 \\
INT & 9.455 & 6.896 & 1.131 & 3.010 & 5.22 & 0.000 \\
TXT & 8.303 & 5.770 & 2.431 & 3.126 & 4.98 & 0.000 \\
SN & 8.212 & 5.985 & 1.950 & 2.847 & 4.80 & 0.000 \\
\hline
\end{tabular}




\subsection{Clusters Characteristics}

As previously seen, only the Unfriendly Users show a statistical difference in demographic variables. Although, we consider that the low sample size compared to the number of Smartphoners profiles is the main reasons for the non-significance of the conducted tests. To better understand Smartphoners belonging to each profile we propose some information about the proposed clusters (Table 11): gender, age, geographical area, brand of the smartphone owned, hours of usage of the smartphone and reason to the use.

Tab. 11 - Descriptive statistics of the clusters

\begin{tabular}{|c|c|c|c|c|c|c|}
\hline Cluster & $\begin{array}{l}\text { Utility } \\
\text { Users }\end{array}$ & Gamers & $\begin{array}{l}\text { Unfriendly } \\
\text { Users }\end{array}$ & $\begin{array}{l}\text { Moderator } \\
\text { Users }\end{array}$ & $\begin{array}{c}\text { Super } \\
\text { Smartphoners }\end{array}$ & $\begin{array}{c}\text { Total } \\
\text { Sample }\end{array}$ \\
\hline Sample & 66 & 33 & 79 & 53 & 33 & 264 \\
\hline \multicolumn{7}{|l|}{ Gender } \\
\hline Male & $72.7 \%$ & $75.8 \%$ & $84.8 \%$ & $69.8 \%$ & $69.7 \%$ & $75.8 \%$ \\
\hline Female & $27.3 \%$ & $24.2 \%$ & $15.2 \%$ & $30.2 \%$ & $30.3 \%$ & $24.2 \%$ \\
\hline \multicolumn{7}{|l|}{ Age } \\
\hline$<35$ years & $59.1 \%$ & $75.8 \%$ & $54.4 \%$ & $69.8 \%$ & $60.6 \%$ & $62.1 \%$ \\
\hline$\geq 35$ years & $40.9 \%$ & $24.2 \%$ & $45.6 \%$ & $30.2 \%$ & $39.4 \%$ & $37.9 \%$ \\
\hline $\begin{array}{l}\text { Average } \\
\text { Age }\end{array}$ & 35 & 29 & 34 & 30 & 34 & 33 \\
\hline \multicolumn{7}{|l|}{ Area } \\
\hline North East & $20 \%$ & $15 \%$ & $33 \%$ & $22 \%$ & $10 \%$ & $62 \%$ \\
\hline North West & $27 \%$ & $4 \%$ & $29 \%$ & $22 \%$ & $18 \%$ & $19 \%$ \\
\hline Center & $36 \%$ & $14 \%$ & $25 \%$ & $7 \%$ & $18 \%$ & $11 \%$ \\
\hline Islands & $38 \%$ & $8 \%$ & $23 \%$ & $15 \%$ & $15 \%$ & $5 \%$ \\
\hline South & $45 \%$ & $9 \%$ & $18 \%$ & $18 \%$ & $9 \%$ & $4 \%$ \\
\hline \multicolumn{7}{|l|}{ Brand } \\
\hline Apple & $57.6 \%$ & $51.5 \%$ & $43.0 \%$ & $54.7 \%$ & $45.5 \%$ & $50.4 \%$ \\
\hline Samsung & $31.8 \%$ & $39.4 \%$ & $38.0 \%$ & $32.1 \%$ & $33.3 \%$ & $34.8 \%$ \\
\hline Others & $10.6 \%$ & $9.1 \%$ & $19.0 \%$ & $13.2 \%$ & $21.2 \%$ & $14.8 \%$ \\
\hline \multicolumn{7}{|l|}{ Usage } \\
\hline 1h/day & $7.6 \%$ & $3.0 \%$ & $17.7 \%$ & $7.5 \%$ & $6.1 \%$ & $9.8 \%$ \\
\hline 1-3h/day & $50.0 \%$ & $42.4 \%$ & $45.6 \%$ & $39.6 \%$ & $36.4 \%$ & $43.9 \%$ \\
\hline 3-5h/day & $15.2 \%$ & $21.2 \%$ & $15.2 \%$ & $30.2 \%$ & $21.2 \%$ & $19.7 \%$ \\
\hline$>5 \mathrm{~h} /$ day & $27.3 \%$ & $33.3 \%$ & $21.5 \%$ & $22.6 \%$ & $36.4 \%$ & $26.5 \%$ \\
\hline \multicolumn{7}{|c|}{ Reason Usage } \\
\hline Work & $15.2 \%$ & $6.1 \%$ & $7.6 \%$ & $7.5 \%$ & $12.1 \%$ & $9.8 \%$ \\
\hline Fun & $28.8 \%$ & $33.3 \%$ & $29.1 \%$ & $26.4 \%$ & $15.2 \%$ & $27.3 \%$ \\
\hline Work\&Fun & $56.1 \%$ & $60.6 \%$ & $63.3 \%$ & $66.0 \%$ & $72.7 \%$ & $62.9 \%$ \\
\hline
\end{tabular}


The Smartphoners: consumer segmentation by smartphone usage

Almost a third of the respondents are Unfriendly Users. This group of consumers really do not like the features of the smartphone and they use it as less as it is possible. As seen, they are mainly adult men without any particular relevance to their geographical location. The brand of the used device seems to be not important for them because mobile devices are scarcely used. Over $17 \%$ of the Unfriendly Users use the smartphone less than 1 hour per day.

The Utility Users represent about a quarter of the surveyed population. They are the older users and are mainly from southern Italy (45\% South, $38 \%$ Islands, 35\% Center). They prefer to use the basic functions of the smartphone i.e. call and browse the internet and their usage of mobile phone is limited to few hours per day. In fact, almost the 58\% of Utility Users use the smartphone less than 3 hours per day. They prefer the iPhone probably due to the brand equity of Apple and they represent the segment of users that use the smartphone for professional reasons.

The Moderator Users are Smartphoners that add to the use of the basic functions of the smartphone (e.g. call, text and browsing) also some hedonic and social functions such as social networks, music and photos. Younger and female characteristics are the most relevant (30.2\%). No particular relevance have been found in terms of geographical location of these users with the exception of the central Italy users that appear to be almost absent in this group of Smartphoners (7\%). More than a half of moderator users handles smartphone more than 3 hours per day.

The two smaller segments of Smartphoners are the Gamers and the Supersmartphoners. They represents only $12 \%$ each of the surveyed population, but due to the growing importance that these profiles will be in the next future, those groups are the most relevant segments identified in this study.

The Gamers are the youngest users (29 years old) and they use smartphone basically for fun, but $61 \%$ of them also use the smartphone also for work. The Gamers have a higher usage of the smartphone - only $3 \%$ of them use mobile devices less than 1 hour/day. The brand of the smartphone owned is important for the Gamers and more than 39\% of them own a Samsung and $51 \%$ an iPhone. Compared to the general distribution of respondents by region, an interesting part of Gamers comes from the islands and the south of Italy.

The Supersmartphoners love in general the multiple functions of their device and more than $72 \%$ of Supersmartphoners use the smartphone for work as well for fun. Their average age is about 34 years old and they are almost equally distributed throughout the national territory. They do not give particular relevance to the brand of their smartphone; in fact, $21 \%$ of them own a smartphone from the two leading brands. The most important characteristic of this segment is their high frequency of usage; more than 
$36 \%$ of Supersmartphoners use mobile phone devices more than 5 hours per day.

\section{Managerial Implications}

The greater importance of smartphoners for the actors of the mobile ecosystem (e.g. handset manufacturers, mobile application providers and telecommunication operators), is pushing the spread of smartphoners segmentation to understand the new trend of users. In fact, innovation in technology is reshaping not only society and ways in which consumer interact each other, but also, ways in which companies (i.e. retailers and manufacturers) engage consumers. We identify differences in the smartphone users' lifestyle that could help actors of the mobile sector to improve their offer. Several managerial implications emerge from this study:

- There is a different usage of the smartphone according to the average age of users. The younger (e.g. the Gamers and the Supersmartphoners) have a strong use of this tool and are open to innovations. To meet these customers' needs, manufacturer should improve the mobile devices offering a higher battery-life or/and an interactive and crisp scree or/and software able to support the game component of the newest mobile applications. Gamers need smartphone with specific screen where images could be seen with a high quality. The feature "colour display" was highlighted as an attribute much appreciate by advanced users (Constantiou et al., 2006). Furthermore, producers need to create new usages of the smartphone, because they have potential customer ready to buy it: the Supersmartphoners. Likewise, mobile application providers should produce apps to enhance their playful component, which are able to engage mostly smartphoners. Particularly Gamers need new approaches and challenges in order to foster more time in playing and of course, in shopping online. Finally, the telecommunication operators should provide faster data access improving connectivity.

- Unfriendly Users and Utility Users require devices, apps and data tariffs that ensure a constant use, although limited, of the mobile device. For example, smartphone producers could offer a mobile phone for the Utility Users, with practical features, with a tariff with short connection to internet and good tariff to call. Unfriendly Users need specific campaign for them with the aim of boosting the use and transforming these consumers into

- Moderate Users is a group of consumers that follow the early adopters, once they have a new usage they try it and enjoy it. They need user- 
The Smartphoners: consumer segmentation by smartphone usage

friendly manual and some tutoring workshops in the place (Koiwumäki et al, 2008) or maybe promote "feature" phones as a final option.

- No age differences have been found between clusters although the younger are the Gamers and the older are the Unfriendly Users. In our opinions it is clear the existence of generational differences between segments of smartphone users. This evidence has strong implications on companies' marketing strategies.

- Another important implication resulting from this study is the absence of a utilitarian segment of Smartphoners. Indeed, none of the identified groups uses the smartphone just for work, except for the Utility Users that have a limited use of multimedia functions. Conversely, the playful component of smartphone usage clearly appears in almost all the segments that have both a personal and professional use of the smartphone. This mix of Work\&Fun seems to symbolize the new challenge to compete on the market place. In recent years, operators who have focused both on the hedonic and utilitarian component of their offer (e.g. Apple and Samsung) are getting the best performance in terms of market share.

- The strong component of the ludic usage of the smartphone and the spread of the multimedia functions directly on the mobile devices open new frontiers to the digital communication by means of music, videos, apps and games able not only to satisfy consumers' needs, but also to engage them. Even the oldest generations seem to be sensitive to these marketing tools.

\section{Limits and Further Research}

In spite of the shown contributions, this paper has several limitations and future deep research is needed.

One of the most important limit of this study is the number of smartphone functions investigated. As previously discussed, smartphone manufacturers and apps providers launch every day several new functions and applications; just few of those have been investigated in this research. Although it is a first attempts to explore to world of smartphone functions, future research is needed to better define how consumers use their mobile device. Functionalities like the e-mail, the alarm, the navigator, the text and documents reader as well as the use of others apps should be depth. A cross-sectional analysis should show changes in usage habits and how new functionalities proposed by manufacturers and apps providers become or not integral part of consumers' lifestyles.

In addition, we suggest paying close attention in defining variables. In our case, the inclusion of two similar variables, as a form of control ("Seek 
Information in the Internet" and "Surf online") lead us to identify different perceived usage in respondents, not only between clusters but also within clusters. Furthermore, the inclusion of a generic function APP may have disturbed results. On the one hand, the function APP puts cognitive limits in the identification of the several features this function includes, but on the other hand, it restricts the absence of the numerous mobile applications that providers launch every day.

As regards the final sample, it includes only Italian people; further researches are needed to be investigated in order to verify different usage between Italian and foreign smartphone users. In fact, a cross-national analysis should highlight behavioural differences between Italian smartphone owners and other countries users. We expect to identify different segments of users in foreign smartphone owners.

Furthermore, the sample size is rather limited to find out demographic and behavioural variables in profile definition. In fact, due to the sample size no statistical differences have been found in the identified segments of smartphone owners. In future, a larger sample size and new demographic and behavioural variables would be investigated.

Although the survey was conducted online, a more representative sample of the wider population of the smartphone owners would be used. On the one hand, the online survey give us the opportunity to reach a more heterogeneous sample, but on the other hand, the final sample size of 264 respondents was insufficient to identify significant findings between five clusters. Given to the huge diversity found between respondents, further research should reach a larger sample to investigate differences between and within groups.

Future studies on psychometric variables should highlight differences of acceptance and usage between segments of smartphone owners. More specifically, due to the social and entertainment value that this product is reaching, it would be interesting to understand how new enjoyable and funny functions can affect users profile, and differ between groups.

\section{Conclusions}

This paper is one of the first attempts to investigate Smartphoners profiles in terms of their usage. The contribution of this research has value both in academia and in management. In fact, mobile marketing literature is growing very fast in the last years and new and interesting contributions are emerging. Furthermore, mobile phones are becoming interesting not only for companies that operate in telecommunication sector, but also for retailers and for manufacturers that should create new touch-points with consumers via smartphone. 
Results show a great diversity in the behavioural characteristics of the five clusters identified creating useful guidelines for the actors of the mobile ecosystem. We pay great attention on two Smartphoners profiles: the Gamers and the super Smartphoners. Although they are the smallest identified groups, we consider that in the next few years those segments will grow rapidly attracting the attention of both scholars and managers. From one side, we have the Supersmartphoners who have an intensive usage of smartphone and seems to be ready to accept any new functionality and innovation the mobile actors would propose them. From the other side, we have the Gamers that appreciate the hedonic aspects of smartphone. Mobile phone device is for them an instrument to enjoy and have fun by playing games. The Gamers represent an interesting target of consumers for the mobile actors who are developing software and hardware components based on hedonic and emotional components to engage the consumer.

\section{References}

Aarnio A., Enkenberg A., Heikkilä J. and Hirvola S. (2002). Adoption and use of mobile services. Empirical evidence from a Finnish survey. Proceedings of the 35th Annual Hawaii International Conference on System Sciences, HICSS 2002, January (1454-1463), doi: 10.1.1.101.7334.

Abascal E., Lautre I.G. and Mallor F. (2006). Data mining in a bicriteria clustering problem. European Journal of Operational Research, 173(3): 705-716, doi: 10.1016/j.ejor.2005.10.006.

Aldhaban F. (2012). Exploring the adoption of Smartphone technology: Literature review. Technology Management for Emerging Technologies (PICMET), 2012 Proceedings of PICMET'12, July (2758-2770).

Balasubramanian S., Peterson R.A. and Jarvenpaa S.L. (2002). Exploring the Implications of M-Commerce for Markets and Marketing. Journal of the Academy of Marketing Science, 30(4): 348-361, doi:10.1177/009207002236910.

Banerjee A. and Ros A.J. (2004). Patterns in global fixed and mobile telecommunications development: a cluster analysis. Telecommunications Policy, 28(2): 107-132.

Bojei J. and Hoo W.C. (2012). Brand equity and current use as the new horizon for repurchase intention of smartphone. International Journal of Business and Society, 13(1): 33-48.

Chang C.Y., Sheu J.P. and Chan T.W. (2003). Concept and design of ad hoc and mobile classrooms. Journal of Computer Assisted Learning, 19(3): 336-46, doi: 10.1046/j.0266-4909.00035.x.

Chang Y.F., Chen C.S. and Zhou H. (2009). Smart phone for mobile commerce. Computer Standards \& Interfaces, 31(4): 740-747. doi:10.1016/j.csi.2008.09.016.

Chen L.D. and Nath R. (2004). A framework for mobile business applications. International Journal of Mobile Communications, 2(4): 368-381, doi: 10.1504/ijmc.2004.005857.

Choi J.H. and Lee H.J. (2012). Facets of simplicity for the smartphone interface: A structural model. International Journal of Human-Computer Studies, 70(2): 129-142, doi: 10.1016/j.ijhcs.2011.09.002. 
Chong A.Y.-L. (2013). Understanding mobile commerce continuance intentions: an empirical analysis of Chinese consumers. Journal of Computer Information Systems, 53(4): 22-30.

ComScore (2014). Retail is the Fastest Growing Usage Category on Smartphones in Italy. Available at: http://www.comscore.com/lat/Insights/Data-Mine/Retail-is-theFastest-Growing-Usage-Category-on-Smartphones-in-Italy (accessed 08/11/2015).

Constantiou I.D., Damsgaard J. and Knutsen L. (2006). Exploring perceptions and use of mobile services: User differences in an advancing market. International Journal of Mobile Communications, 4(3), 231-247, doi: 10.1504/IJMC.2006.008940.

De Canio F., Ieva M. and Ziliani, C. (2015). Device usage patterns and online shopping behaviour. Proceedings of the XII annual Conference Società Italiana Marketing.

De Gusta M. (2012). Are Smart Phones Spreading Faster than Any Technology in Human History? Available at: http://www.technologyreview.com/news/427787/ are-smart-phones-spreading-faster-than-any-technology-in-human-history/ (accessed 08/11/2015).

De Marez L., Vyncke, P., Berte K., Schuurman D. and De Moor K. (2007). Adopter segments, adoption determinants and mobile marketing. Journal of Targeting, Measurement and Analysis for Marketing, 16(1): 78-95, doi: 10.1057/palgrave.jt.5750057.

Figge S. (2004). Situation-dependent services: a challenge for mobile network operators. Journal of Business Research, 57(12): 1416-1422, doi: 10.1016/S01482963(02)00431-9.

Goneos-Malka A., Strasheim A. and Grobler A.F. (2014). Conventionalists, connectors, Technoisseurs and Mobilarti: Differential profiles of mobile marketing segments based on phone features and postmodern characteristics of consumers. Journal of Retailing and Consumer Services, 21(6): 905-916, doi: 10.1016/j.jretconser.2014.08.008

Google (2012). The New Multi-Screen World. http://ssl.gstatic.com/think/docs/thenew-multi-screen-world-study_research-studies.pdf.

Groß M. (2015). Mobile shopping: a classification framework and literature review. International Journal of Retail and Distribution Management, 43(3): 221-241, doi: 10.1108/ijrdm-06-2013-0119.

GSMA (2015). The Mobile Economy. Available at: http://www.gsmamobile economy.com/GSMA_Global_Mobile_Economy_Report_2015.pdf (accessed 04/11/2015).

Hair J.F., Rolph E., Anderson R.L., Tatham R.L. and William C.B. (1998). Multivariate Analysis. Englewood Cliffs, NJ: Prentice Hall International.

Hamka F., Bouwman H., De Reuve M. and Kroesen M. (2014). Mobile customer segmentation based on smartphone measurement. Telematics and Informatics, 31(2): 220-227, doi: 10.1016/j.tele.2013.08.006.

Hill T.R. and Roldan M. (2005). Toward third generation threaded discussions for mobile learning: opportunities and challenges for ubiquitous collaborative environments. Information Systems Frontiers, 7(1): 55-70, doi: 10.1007/s10796005-5338-7.

Hung M.C., Yang S.T. and Hsieh T.C. (2012). An examination of the determinants of mobile shopping continuance. International Journal of Electronic Business Management, 10(1): 29-37.

Kang Y.M., Cho C. and Lee S. (2011). Analysis of factors affecting the adoption of smartphones. In Technology Management Conference (ITMC), 2011 IEEE International, June (919-925). 
Karaatli G. and Veryzer R.W. (2012). The effects of electronic decision aids on consumers' cue utilization in product evaluations. Journal of Marketing Development and Competitiveness, 6(1): 74-80.

Kim Y.H., Kim D.J. and Wachter K. (2013). A study of mobile user engagement (MoEN): Engagement motivations, perceived value, satisfaction, and continued engagement intention. Decision Support Systems, 56: 361-370, doi: 10.1016/j.dss.2013.07.002.

Koivumäki T., Ristola A. and Kesti M. (2008). The perceptions towards mobile services: An empirical analysis of the role of use facilitators. Personal \& Ubiquitous Computing, 12(1): 67-75, doi: 10.1007/s00779-006-0128-x.

Kotler P. (2003). Marketing Management. Evanston: Prentice Hall.

Kumar S. and Zahn C. (2003). Mobile communications: evolution and impact on business operations. Technovation, 23(6): 515-520, doi:10.1016/S01664972(02)00120-7.

Lebart L., Morineau A., Lambert T. and Pleuvret P. (2001). Manuel de référence de $S P A D$. Montreuil: Centre International de Statistique et d'Informatique Appliquées, CISIA-CERESTA.

Lin Q. (2007). Mobile Customer Clustering Analysis Based on Call Detail Records. Communications of the IIMA, 7(4): article 11, doi: 11.10.1109/icmss.2009.5302716.

Lu H.P. and Su Y.-J. (2009). Factors affecting purchase intention on mobile shopping web sites. Internet Research, 19(4): 442-458, doi: 10.1108/10662240910981399.

Mamaar Z. (2003). Commerce, E-commerce, and M-commerce: what comes next? Communications of the ACM, 46(12): 251-257, doi: 10.1145/953460.953508.

Monti E. (2013). Million dollar expense: buying out the app store. Available at: https://gigaom.com/2013/09/29/million-dollar-expense-buying-out-the-app-store/ (accessed 07/11/2015).

Muk A. (2007). Cultural influences on adoption of SMS advertising: a study of American and Taiwanese consumers. Journal of Targeting, Measurement and Analysis for Marketing, 16(1): 39-47, doi: 10.1057/palgrave.jt.5750062.

Nakache J. and Confais J. (2000). Méthodes de classification: Avec illustrations SPAD et SAS. Montreuil: Centre International de Statistique et d'Informatique Appliquées, CISIA-CERESTA.

Park Y. and Chen J.V. (2007). Acceptance and adoption of the innovative use of smartphone. Industrial Management \& Data Systems, 107(9): 1349-1365, doi: 10.1108/02635570710834009.

Persaud A. and Azhar I. (2012). Innovative mobile marketing via smartphones: are consumers ready? Marketing Intelligence and Planning, 30(4): 418-443, doi: 10.1108/02634501211231883.

Rogers E.M. (1995). Diffusion of Innovations (4 ${ }^{\text {th }}$ ed.). New York: the Free Press.

Roschelle J. (2003). Keynote paper: unlocking the learning value of wireless mobile devices. Journal of Computer Assisted Learning, 19(3): 260-72, doi: 10.1046/j.0266-4909.2003.00028.x.

Scott A.J. and Knott M. (1974). A cluster analysis method for grouping means in the analysis of variance. Biometrics, 30(3): 507-512, doi: 10.1080/03601234.2015.965621.

Sell A., Mezei J. and Walden P. (2014). An attitude-based latent class segmentation analysis of mobile phone users. Telematics and Informatics, 31(2): 209-219, doi: 10.1016/j.tele.2013.08.004. 
Sell A., Walden P. and Carlsson C. (2010). Are You Efficient, Trendy or Skillfull? An Exploratory Segmentation of Mobile Service Users. In Mobile Business and 2010 Ninth Global Mobility Roundtable (ICMB-GMR), (116-123), IEEE, doi: 10.4018/jssoe.2011070101.

Shankar V. and Balasubramanian S. (2009). Mobile marketing: a synthesis and prognosis. Journal of Interactive Marketing, 23(2): 118-129, doi: 10.1016/j.intmar.2009.02.002.

Shankar V., Venkatesh A., Hofacker C. and Naik P. (2010). Mobile marketing in the retailing environment: current insights and future research avenues. Journal of interactive marketing, 24(2): 111-120, doi:10.1016/j.intmar.2010.02.006

Smith W.R. (1956). Product differentiation and market segmentation as alternative marketing strategies. Journal of Marketing, 21(1): 3-8.

Ström R., Vendel M. and Bredican J. (2014). Mobile Marketing: a literature review on its value for consumers. Journal of Retailing and Consumer Service, 21(6): 10011012, doi: 10.1016/j.jretconser.2013.12.003.

The Economist (2015). Planet of the phones. Available at: http://www.economist.com/ news/leaders/21645180-smartphone-ubiquitous-addictive-and-transformativeplanet-phones (accessed 04/11/2015).

Vanden Abeele M., Antheunis M.L. and Schouten A.P. (2014). Me, myself and my mobile: A segmentation of youths based on their attitudes towards the mobile phone as a status instrument. Telematics and Informatics, 31(2): 194-208. doi: 10.1016/j.tele.2013.04.004

Venkatesh R. (2015). Mobile Marketing From Marketing Strategy to Mobile Marketing Campaign Implementation. International Journal of Research, 2(2): 1175-1187.

Verhoef P.C., Kannan P.K. and Inman J.J. (2015). From multi-channel retailing to omni-channel retailing: Introduction to the special issue on multi-channel retailing. Journal of Retailing, 91(2): 174-181. doi: 10.1016/j.jretai.2015.02.005.

Verkasalo H., López-Nicolás C., Molina-Castillo F.J. and Bouwman H. (2010). Analysis of users and non-users of smartphone applications. Telematics and Informatics, 27(3): 242-255, doi: 10.1016/j.tele.2009.11.001.

Wedel M. and Kamakura W.A. (2000). Market segmentation: Conceptual and methodological foundations ( $2^{\text {nd }}$ ed.). New York: Springer Science \& Business Media.

Yoo J., Yoon Y. and Choi M. (2010). Importance of positive reputation for Smartphone adoption. Information and Communication Technology Convergence (ICTC), 2010 International Conference on 17-19 November (314-318), doi: 10.1109/ICTC.2010.5674690.

Zhang J., Farris P.W., Irvin J.W., Kushwaha T., Steenburgh T.J. and Weitz B.A. (2010). Crafting Integrated Multichannel retailing strategies. Journal of Interactive Marketing, 24(2): 168-180, doi: 10.1016/j.intmar.2010.02.002.

Zheng P. and Ni L.M. (2006). Spotlight: the rise of the smart phone. IEEE Distributed Systems Online, 7(3), art. no. 0603-03003. 